\title{
Loss of resistance to normal saline is preferred to identify the epidural space: a survey of Canadian pediatric anesthesiologists
}

[La perte de résistance au soluté physiologique est la technique préférée pour identifier

l'espace péridural : une enquête auprès des anesthésiologistes pédiatriques canadiens]

Warwick A. Ames mbBs FrCA, Jason A. Hayes MD FrCPC, Guy C. Pétroz MD, W. Lawrence Roy MD FrCPC

Purpose: Several methods have been described to locate the epidural space, but the loss-of-resistance (LOR) technique is the most commonly used. Expert opinion states that LOR to air is the best medium for neonates and infants. We conducted a Canadawide postal survey to determine the current state of practice for placement of epidural catheters in pediatric patients.

Methods: Two hundred and nine surveys were distributed to academic pediatric anesthesiologists across Canada. The survey was limited to six questions and was anonymous.

Results: The response rate was $62.2 \%$. LOR was the method of choice for 124/130 anesthesiologists (95.4\%). LOR to normal saline was the medium of choice for all age groups, although LOR to air and LOR to air/saline gained in popularity with increasing patient age. The majority of anesthesiologists do not change their LOR technique for different patient ages or level of epidural insertion. Most responders ranked 'training' as the most important determinant of practice, whereas 'departmental guidelines' were considered the least important. No complication attributable to the LOR technique used was reported.

Conclusion: LOR to normal saline is the preferred method for identification of the epidural space in children of all age groups. The suggestion by experts that LOR to air should be used in neonates and infants was not supported by the practice of pediatric anesthesiologists across Canada.

Objectif : Parmi les méthodes décrites pour localiser l'espace péridural, la technique de la perte de résistance (PDR) est la plus courante. Un rapport d'expert souligne que la PDR à l'air est le meilleur moyen à utiliser chez les nouveau-nés et les jeunes enfants. Nous avons mené une enquête pancanadienne pour décrire l'utilisation actuelle de cathéters périduraux en pédiatrie.
Méthode : Deux cent neuf formulaires d'enquête ont été distribués aux anesthésiologistes de pédiatrie universitaire à travers le Canada. L'enquête, anonyme, ne comportait que six questions.

Résultats : Le taux de réponse a été de 62,2\%. La PDR était la méthode de choix de 124/I30 anesthésiologistes (95,4\%). La PDR au soluté physiologique était préféré pour tous les groupes d'âge, même si la PDR à l'air et la PDR à l'airlau soluté physiologique devenaient plus populaires avec l'âge croissant des patients. La majorité des répondants ne changent pas leur technique de PDR en fonction de l'âge des patients ou du niveau d'insertion péridurale. La plupart ont classé «la formation» en tête des déterminants de la pratique, tandis que «les directives du département» étaient considérées comme les moins importantes. II n'y a eu aucune complication liée à la technique de PDR.

Conclusion : La PDR au soluté physiologique est la méthode préférée pour identifier l'espace péridural chez les enfants de tous âges. L'opinion des experts voulant que la PDR à l'air doive être utilisée chez les nouveau-nés et les jeunes enfants n'est pas suivie par les anesthésiologistes pédiatriques canadiens.

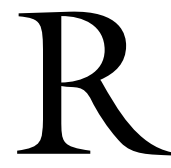

EGIONAL anesthesia, in particular the use of epidural analgesia, has become an integral part of anesthesia practice. Several methods have been described for locating the epidural space but loss-of-resistance(LOR), first described in 1933 by Dogliotti, ${ }^{1}$ is the most widely used technique. ${ }^{2}$ Recently, LOR to normal saline (LORNS) has been advocated as the technique of choice in adult

From the Department of Anesthesia, Hospital for Sick Children, Toronto, Ontario, Canada.

Address correspondence to: Dr. Warwick A. Ames, Department of Anesthesia, Hospital for Sick Children, 555 University Avenue,

Toronto, Ontario M5G 1X8, Canada. Phone: 416-813-8963; Fax: 416-813-7445; E-mail: wads@doctors.org.uk; ames0002@mc.duke.edu Accepted for publication November 25, 2004.

Revision accepted February 18, 2005. 


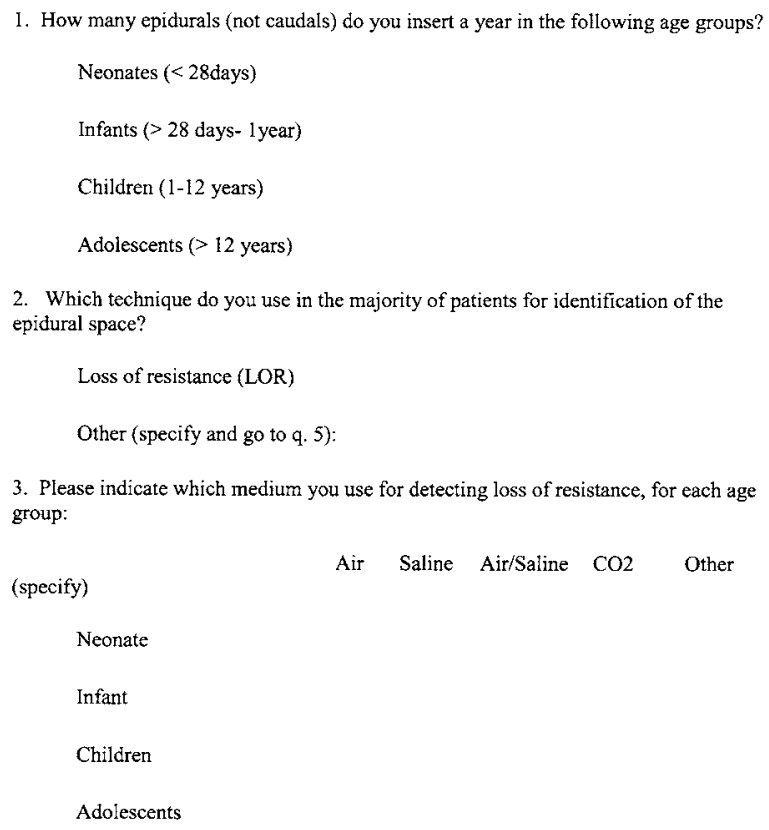

4. Do you change your LOR technique with the level of epidural insertion (for example thoracic versus lumbar)?

6. Has any patient, under your care, experienced any of the following adverse events following epidural insertion? (Please give details although avoid any information that may directly identify the patient)

Peripheral nerve / root injury with neurological sequelae

Spinal cord injury with neurological sequelae

Infection (epidural abscess / arachniditis)

Pneumocephalus (air in the subarachnoid space)

Venous air embolism

Other (please specify)

FIGURE 1 The English version of the questionnaire used in this study. anesthesia. ${ }^{2-4}$ However there is conflicting literature as to which medium is the most appropriate for the placement of epidural catheters in pediatric patients..$^{2,5-9} \mathrm{We}$ were interested by the expert recommendation that detection of the epidural space with LORNS is preferable in adolescents but has limitations in infants and young children. ${ }^{10}$ A nation-wide postal survey was conducted to determine the current practice for placement of epidural catheters in pediatric patients, with a specific focus on the LOR medium used.

\section{Methods}

The goal was to contact every university-affiliated anesthesiologist practicing pediatric anesthesia in Canada. Using the Association of Canadian University Departments of Anesthesia (ACUDA) web site (www.anesthesia.org/acuda), we contacted the Chair of each university department of anesthesia to identify which academic hospitals offered pediatric anesthesia services. Each hospital was then contacted by telephone and the number of pediatric anesthesiologists in each department was established. The surveys were sent with a stamped addressed envelope and cover letter identifying the authors and our affiliation with a university teaching hospital. A duplicate version translated into French was sent to the three French-speaking university hospitals in the province of Quebec. Approximately eight weeks later the same survey was redistributed to this province due to a poor initial response. A cover letter was attached that clearly stated this was the second mailing, and that the recipient should complete the survey only if they did not respond previously.

\section{The questionnaire}

Pediatric patients were classified into four groups: neonates ( $<28$ days), infants ( 28 days -1 yr), children (1-12 yr), and adolescents (> $12 \mathrm{yr}$ ). The questionnaire is shown in Figure 1. It was distributed in March of 2004 with the follow up distribution, six weeks later. The survey was anonymous.

\section{Data analysis}

Questionnaire data were inserted into a spreadsheet. Cross tabulation and descriptive statistical analyses were performed using Microsoft Excel(C) (Microsoft Corp., Redmond, WA, USA) and Graph Pad Prism (C version 4 (GraphPad Software, Inc., San Diego, CA, USA).

\section{Results}

Two hundred and nine surveys were distributed nationwide to the target population identified above. The initial response rate was $53 \%$. Following the sec- 
TABLE The number of epidurals performed per annum for each age group

\begin{tabular}{llll}
\hline Patient group & $\begin{array}{l}\text { Number of anesthesiologists } \\
\text { performing epidurals }\end{array}$ & $\begin{array}{l}\text { Mean } \\
\pm S D\end{array}$ & Median \\
\hline Neonates & 38 & $3.1 \pm 2.9$ & 2.0 \\
Infants & 83 & $5.2 \pm 4.7$ & 4.0 \\
Children & 117 & $10.3 \pm 8.8$ & 10.0 \\
Adolescents & 116 & $10.5 \pm 9.7$ & 8.0 \\
\hline
\end{tabular}

ond distribution to Quebec, the overall national return rate was $62.2 \%$ (130 responses) at the time of study closure.

\section{Number of epidurals inserted per annum}

The number of epidurals performed in each age group is presented in the Table. Only $38 / 130(29 \%)$ insert epidural catheters in neonates, the average being three epidurals per year. The median number of epidurals performed in each age group was consistently less than the mean.

\section{Technique used to identify the epidural space}

LOR was the method of choice for 124/130 anesthesiologists $(95.4 \%)$. Other techniques described included the 'hanging drop' method. The 'Tsui' technique was used by three physicians to place lumbar and thoracic epidural catheters via the caudal route in neonates and children up to two years of age.

LORNS was the medium of choice for all age groups, although LOR to air (LORA) and LOR to air/saline (LORA/S) gained in popularity with increasing patient age. LOR to carbon dioxide $\left(\mathrm{CO}_{2}\right)$ was used infrequently in neonates, infants and children, and not at all in the adolescent group. LORA was more popular than LORA/S in children and adolescents. (Figure 2).

\section{Change of technique with patient age}

Twenty (15.4\%) anesthesiologists changed their LOR technique depending upon the age of the patient. Figure 3 illustrates the change in practice: LORNS was the preferred technique for neonates whilst LORA was not used at all. The converse was noted in older children, when these clinicians would change to LORA or LORA/S.

\section{Change of technique depending upon the level of inser-} tion

Ninety-eight percent of the responders to the survey did not alter their technique for insertion of epidural

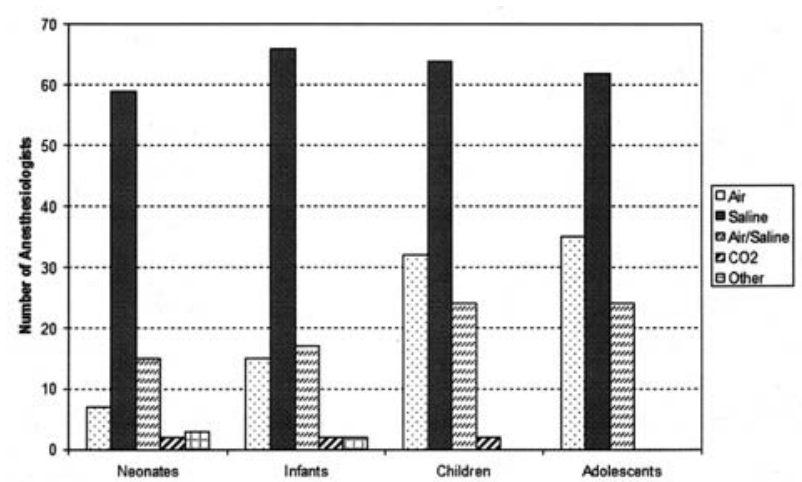

FIGURE 2 The number of anesthesiologists using each loss of resistance (LOR) and 'other' techniques according to patient age.

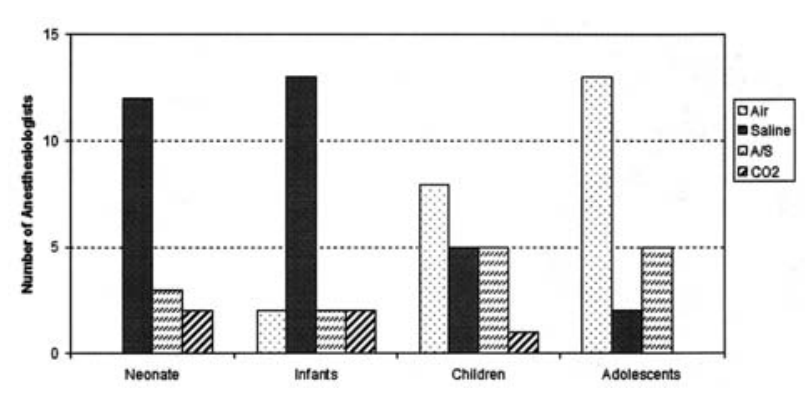

FIGURE 3 The loss of resistance (LOR) medium used by the anesthesiologists $(n=20)$ who changed their technique with patient age.

catheters at different spinal levels. Of those who did, one practitioner changed from LORA for lumbar epidurals, to the hanging drop method, with the patient sitting and breathing spontaneously, for thoracic epidurals. Another responder stated that he/she preferred LORA for thoracic epidurals, but would not use air for a neonate or for any person with known congenital heart disease or a patent foramen ovale.

\section{Factors that determined practice and technique}

Factors that influenced practice are shown in Figure 4. Overall, 'training' was considered the most important determinant of practice whilst 'departmental guidelines' was considered the least important. However, only three physicians reported that guidelines existed within their department. 


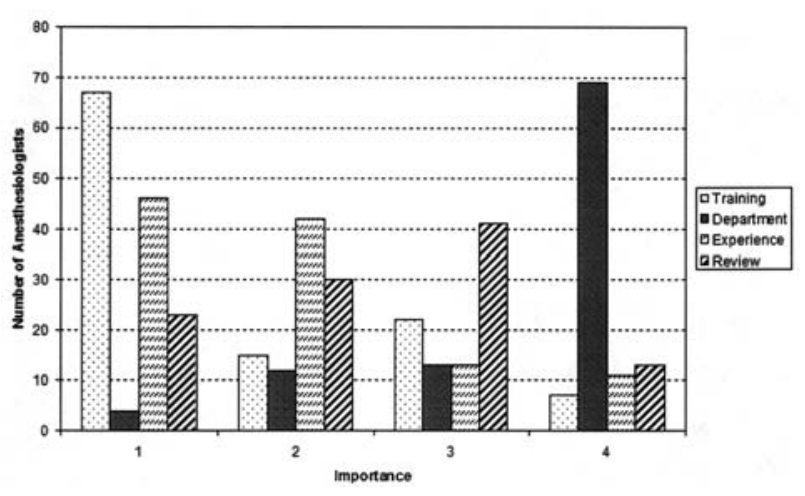

FIGURE 4 Factors which influenced the choice of loss of resistance (LOR) technique. Level of importance is graded from 1 (most important) to 4 (least important).

\section{Complications of epidural anesthesia and association with technique}

The number of complications reported was minimal and none were definitively attributable to the technique used to identify the epidural space.

\section{Discussion}

Our goal was to question the expert opinion that LORNS should be used to detect the epidural space in adolescents but not in infants and small children in whom LORA would be preferable. We undertook a postal survey in order to determine the practice patterns of pediatric anesthesiologists in Canada. We used established methods to obtain a satisfactory response rate. ${ }^{11}$ Our main finding was that LORNS is the preferred method for identification of the epidural space in children of all age groups.

Continuous lumbar epidural anesthesia and analgesia is now well documented in the pediatric anesthesia literature. ${ }^{12,13}$ The results of our survey suggest that although epidural use is common in pediatric patients in Canada, the practice is predominantly reserved for older children and adolescents. Only $29 \%$ of the surveyed anesthesiologists placed epidurals in neonates and then, on average, only three per annum. No guidelines exist that state how many epidurals should be performed annually to maintain competency. There is, however, evidence that between 45 and 60 epidurals are required for an anesthesiology resident to achieve a consistent performance. ${ }^{14}$

There are a number of methods used to identify the epidural space in children including LOR, the "hanging-drop" 15 and the "drip and tube" method."
According to our survey, the LOR technique is the method of choice, but controversy remains as to which LOR medium is most appropriate. ${ }^{5,6,10}$ This is due in part to the fact that pediatric patients are a diverse group in terms of anatomy and physiology. In neonates, for example, the spinal ligaments are softer and less densely packed compared to older children, so that the end-point of a LOR technique is less well defined. ${ }^{10}$ The distance from the skin to the epidural space can be strikingly small ${ }^{16}$ and a relatively low cerebrospinal fluid pressure in neonates and infants may make identification of an accidental dural tap more difficult. ${ }^{17}$ Therefore it is suggested that air is safer than saline, for identification of the epidural space, in children less than two years of age..$^{10,17} \mathrm{We}$ observed however that LORNS was the most popular technique amongst pediatric anesthesiologists practicing in Canada, and not just for neonates but for all age groups. Even the 20 anesthesiologists who changed their practice (depending on patient age) preferred LORNS for identification of the epidural space in neonates and infants. This is in direct contrast to the technique suggested in the literature. ${ }^{17}$

It is not surprising that 'review of the literature' and 'department guidelines' were the least important determinants of practice. Instead physicians responding to this questionnaire based their practice upon 'training' and 'experience'. Since training appears to be the most important factor determining practice, it is incumbent upon supervisors to be certain of the safety and efficacy of one technique over another. It is essential not to promote a method which has disadvantages and serious complications associated with its use, if there is a safer alternative. ${ }^{18}$ Which technique, therefore, in the pediatric population is safer: LORA or LORNS?

Air is said to be preferred over saline for a few reasons. Air is readily available and cannot be confused for another substance. Busoni reported that in over 10,000 epidurals in pediatric patients, there were no complications associated with the use of LORA. ${ }^{5}$ Air may permit easier detection of a dural tap compared to saline ${ }^{19}$ and the actual incidence of dural puncture in pediatric patients is greater with LORNS. ${ }^{20}$ This is in direct contrast to adult patients in whom the continuous pressure of the saline technique pushes the dura away and so reduces the risk of dural puncture. ${ }^{19,21}$ However LORA is associated with numerous complications that include venous air embolism (VAE), nerve root compression, sc emphysema, pneumocephalus, a greater incidence of incomplete analgesia and a higher incidence of paresthesia. ${ }^{2}$

In the pediatric population, VAE is a major source of concern. Two case reports describe suspected VAE with 
the use of LORA in pediatric patients which resulted in hemodynamic instability.7,22 The volume of air required to produce right ventricular dysfunction in humans is unknown, although the lowest volume required in dogs is $0.5 \mathrm{~mL} \cdot \mathrm{kg}^{-1} \cdot \mathrm{min}^{-1} .{ }^{23} \mathrm{~A}$ probe patent foramen ovale exists in $50 \%$ of children up to five years of age which can open intermittently during crying and therefore risk embolization of air into the systemic circulation. ${ }^{24}$ Even air injected into the epidural space, which is absorbed by the epidural veins, is detectable on transesophageal echocardiography. ${ }^{25,26}$ Considering the potential morbidity of acute VAE, every attempt should be made to limit or completely avoid the introduction of air into the epidural space.

Incomplete analgesia is also associated with the use of LORA and is well reported in both adults and children. ${ }^{20,27}$ The problem may be worse in young children because the epidural space extends further along the spinal nerves, and this may facilitate air trapping. Also, the space is smaller and the same volume of air would cause a greater disruption.

The concerns over the use of the LORA technique has lead to other media being advocated. ${ }^{20}$ LOR to $\mathrm{CO}_{2}$ has some theoretical advantages: first, it is extremely soluble in blood and therefore will not result in bubbles and their subsequent adverse consequences; and second, it may be bactericidal. ${ }^{17}$ However, $\mathrm{CO}_{2}$ may be somewhat impractical to use as it is not as readily available as air or saline. Only two pediatric anesthesiologists in our survey use LOR to $\mathrm{CO}_{2}$.

More recently, LORA/S has been suggested as a safer technique for all patients. ${ }^{6}$ The combination of air and saline allows for the "feel" of air in the syringe while reducing the risk of injecting air when the epidural space is entered. Also, less saline is injected so that the diagnosis of a dural tap may be easier and dilution of local anesthetic is minimized. According to our results, this technique is used by almost $20 \%$ of pediatric anesthesiologists practicing in Canada.

Finally, the number of complications reported in our survey was low, with no obvious association between the techniques used. It appears that regional anesthesia is safe and many studies support this fact. ${ }^{28-30} \mathrm{~A}$ review of the literature by Shenouda et al. compared complication rates between LORA and LORNS in both adult and pediatric patients. ${ }^{3}$ They found 22 reported complications with air compared to one with saline, and concluded that the literature supports not only improved analgesia but decreased morbidity with LORNS compared to LORA. In a survey of epidural analgesia use in children from the UK, no adverse consequences to the use of air were reported, although only $17 \%$ of responders used LORA as their insertion technique. ${ }^{31}$ Finally, a large retrospective study of pediatric epidural analgesia practice reported five severe neurological accidents. ${ }^{8}$ LORA was used in four of the patients (the fifth was unknown). The authors stated that it was impossible to exclude the possibility that an air bubble trapped in an epidural vein caused local thrombosis and spinal ischemia, and this prompted the authors to suggest that it was safer to use saline in neonates and infants instead of air.

\section{Summary}

It is apparent that LORNS is the preferred method for identification of the epidural space in children of all age groups. The recommendation that LORA should be used to identify the epidural space in neonates and infants is not supported by the practice of pediatric anesthesiologists across Canada. We believe that in view of the potential for complications using LORA, LORNS is the safest technique in children of all ages. A larger randomized controlled study amongst pediatric institutions, however, would be required to confirm this suggestion.

\section{References}

1 Dogliotti AM. A new method of block anesthesia. Segmental peridural spinal anesthesia. Am J Surg 1933; 20: 107-8.

2 Saberski LR, Kondamuri S, Osinubi OY. Identification of the epidural space: is loss of resistance to air a safe technique? A review of the complications related to the use of air. Reg Anesth 1997; 22: 3-15.

3 Shenouda PE, Cunningham BJ. Assessing the superiority of saline versus air for use in the epidural loss of resistance technique: a literature review. Reg Anesth Pain Med 2003; 28: 48-53.

4 Beilin Y, Arnold I, Telfeyan C, Bernstein HH, Hossain $S$. Quality of analgesia when air versus saline is used for identification of the epidural space in the parturient. Reg Anesth Pain Med 2000; 25: 596-9.

5 Busoni P, Messeri A. Loss of resistance technique to air for identifying the epidural space in infants and children. Use an appropriate technique! (Letter). Paediatr Anaesth 1995; 5: 397.

6 Roelants F, Veyckemans F, Van Obbergh L, et al. Loss of resistance to saline with a bubble of air to identify the epidural space in infants and children: a prospective study. Anesth Analg 2000; 90: 59-61.

7 Schwartz N, Eisenkraft JB. Probable venous air embolism during epidural placement in an infant. Anesth Analg 1993; 76: 1136-8.

8 Flandin-Blety C, Barrier G. Accidents following extradural analgesia in children. The results of a retrospective study. Paediatr Anaesth 1995; 5: 41-6. 
9 Yamashita $M$, Tsuji $M$. Identification of the epidural space in children. The application of a micro-drip infusion set. Anaesthesia 1991; 46: 872-4.

10 Bissonnette B, Dalens D. Pediatric Anesthesia. Principles and Practice. McGraw-Hill; 2002.

11 Edwards P, Roberts I, Clarke $M$, et al. Increasing response rates to postal questionnaires: systematic review. BMJ 2002; 324: 1183.

12 Dalens B, Tanguy A, Haberer JP. Lumbar epidural anesthesia for operative and postoperative pain relief in infants and young children. Anesth Analg 1986; 65: 1069-73.

13 Chalkiadis $G$. The rise and fall of continuous epidural infusions in children (Editorial). Paediatr Anaesth 2003; 13: 91-3.

14 Kopacz DJ, Neal JM, Pollock JE. The regional anesthesia "learning curve". What is the minimum number of epidural and spinal blocks to reach consistency? Reg Anesth 1996; 21: 182-90.

15 Ruston FG. Epidural anaesthesia in infants and children. Can Anaesth Soc J 1954; 1: 37-44.

16 Yaster M, Maxwell LG. Pediatric regional anesthesia. Anesthesiology 1989; 70: 324-38.

17 Dalens B. Regional anesthesia in children. Anesth Analg 1989; 68: 654-72.

18 rentis SM. Time to abandon loss of resistance to air (Letter). Anaesthesia 1997; 52: 184.

19 Russell R, Douglas J. Loss of resistance to saline is better than air for obstetric epidurals. Int J Obstet Anesth 2001; 10: 302-6.

20 Dalens B, Chrysostome $\Upsilon$. Intervertebral epidural anaesthesia in paediatric surgery: success rate and adverse effects in 650 consecutive procedures. Paediatr Anaesth 1991; 1: 107-17.

21 Stride PC, Cooper GM. Dural taps revisited. A 20-year survey from Birmingham Maternity Hospital.

Anaesthesia 1993; 48: 247-55.

22 Guinard JP, Borboen M. Probable venous air embolism during caudal anesthesia in a child. Anesth Analg 1993; 76: 1134-5.

23 Adornato DC, Gildenburg PL, Ferrario CM, Smart J, Frost EA. Pathophysiology of intravenous air embolism in dogs. Anesthesiology 1978; 49: 120-7.

24 Sethna NF, Berde CB. Venous air embolism during identification of the epidural space in children. Anesth Analg 1993; 76: 925-7.

25 Naulty JS, Ostheimer GW, Datta S, Knapp R, Weiss JB. Incidence of venous air embolism during epidural catheter insertion. Anesthesiology 1982; 57: 410-2.

26 Jaffe RA, Siegel LC, Schnittger I, Propst JW, Brock-Utne $J G$. Epidural air injection assessed by transesophageal echocardiography. Reg Anesth 1995; 20: 152-5.

27 Dalens B, Bazin JE, Haberer JP. Epidural bubbles as a cause of incomplete analgesia during epidural anesthesia. Anesth Analg 1987; 66: 679-83.

28 Tobias JD, Lowe S, O’Dell N, Holcomb GW. Thoracic epidural anaesthesia in infants and children. Can J Anaesth 1993; 40: 879-82.

29 Strafford MA, Wilder RT, Berde CB. The risk of infection from epidural analgesia in children: a review of 1620 cases. Anesth Analg 1995; 80: 234-8.

30 Osaka $\Upsilon$, Yamashita $M$. Intervertebral epidural anesthesia in 2,050 infants and children using the drip and tube method. Reg Anesth Pain Med 2003; 28: 103-7.

31 Williams DG, Howard RF. Epidural analgesia in children. A survey of current opinions and practices amongst UK paediatric anaesthetists. Paediatr Anaesth 2003; 13: 769-76. 